\title{
Lithium perrhenate catalyst for carbon aerogel-based supercapacitor
}

\author{
Mateusz Ciszewski $^{1}$ (D) $\cdot$ Andrzej Koszorek $^{2} \cdot$ Małgorzata Osadnik $^{3} \cdot$ Katarzyna Szleper $^{4} \cdot$ Michał Drzazga $^{1}$. \\ Katarzyna Leszczyńska-Sejda ${ }^{1}$
}

Received: 19 January 2020 / Accepted: 26 March 2020 / Published online: 1 April 2020

(c) The Author(s) 2020 OPEN

\begin{abstract}
Carbon aerogels are unique type of amorphous carbon-based materials with an extraordinary properties including light weight, well-developed and tailored pore structure, high specific surface area, low electrical resistivity and high purity. Therefore carbon aerogels can be used in numerous applications, including energy storage materials such as supercapacitors or lithium-ion batteries. Synthesis of hydrogel requires accurate concentration of monomers and catalysts, exact temperature and time. Low-density carbon aerogel can be produced using a complicated supercritical drying method, which allows to expel solvent without carbon porous structure collapse. Here we report a possibility to use novel type of resorcinol/formaldehyde gelation catalyst based on rhenium salt. The organic gel obtained using lithium perrhenate was traditionally carbonized and examined with respect to energy storage properties. It was found that interaction of lithium and rhenium atoms with monomers resulted in completely different structure than using typical sodium carbonate catalyst.
\end{abstract}

$\triangle$ Mateusz Ciszewski, mateuszc@imn.gliwice.pl| 'Department of Hydrometallurgy, Łukasiewicz Research Network—Institute of Non-Ferrous Metals, Sowińskiego 5, 44-100 Gliwice, Poland. ²Department of Inorganic Chemistry, Analytical Chemistry and Electrochemistry, Silesian University of Technology, B. Krzywoustego 6, 44-100 Gliwice, Poland. ${ }^{3}$ Department of Powder and Composite Materials, Łukasiewicz Research Network—Institute of Non-Ferrous Metals, Sowińskiego 5, 44-100 Gliwice, Poland. ${ }^{4}$ Faculty of Chemistry, Silesian University of Technology, Marcina Strzody 9, 44-100 Gliwice, Poland. 


\section{Graphic abstract}

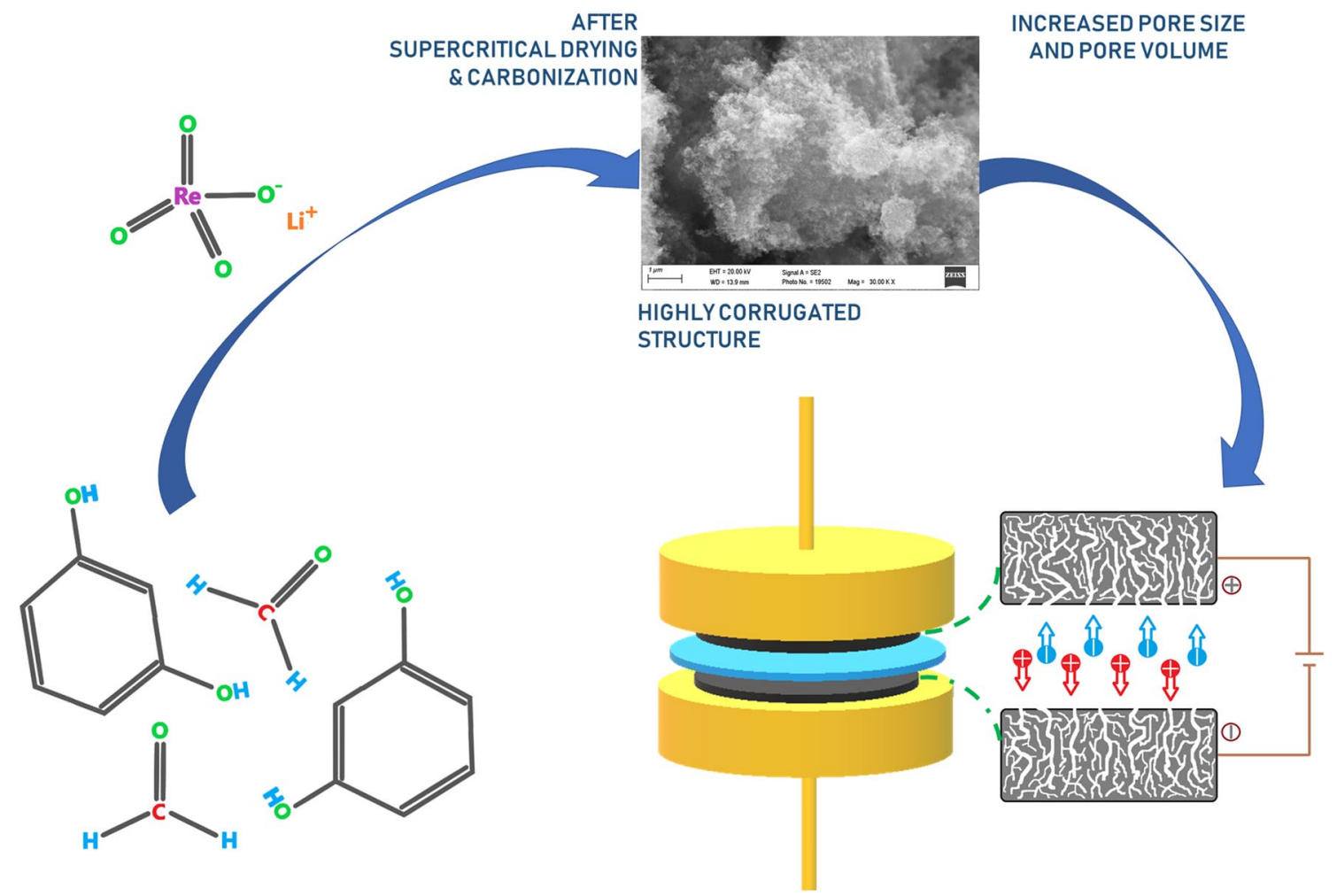

Keywords Supercapacitors · Carbon aerogels · Supercritical drying · Lithium perrhenate

\section{Introduction}

Although carbon aerogel is extraordinary material that may find application in numerous areas of everyday living it's large-scale production is limited because of complex and sophisticated apparatus required for drying procedures (high $\mathrm{T}$ and $\mathrm{p}$ autoclaves to maintain supercritical solvent parameters). Regardless complex apparatus carbon aerogels can be successfully applied in the energy storage applications, specifically in double layer capacitors. Gels are characterised by low electrical resistivity, tailored pores structure, high surface area, purity of carbonized material, and light weight that make carbon gels one of the best candidates for supercapacitors. The methodology to obtain high quality tailored material in a facile way is still under consideration. The history of gels, specifically inorganic gels, had been triggered by Steven Kistler who proposed the method to obtain silica gel from water glass in a hydrochloric acid-catalyzed process. He stated that the key step in gel synthesis is a proper drying procedure preceded by aging. Cross-linking and polimerisation of precursors are processes responsible for slight shrinking of material, known as syneresis, which allows to take material out from the container. In the next step material is dried. As the simple water evaporation leads to significant shrinkage of material and severe damages, Kistler proposed firstly to replace water by another solvent that can be further exchanged by a gas. Based on this procedure liquid is replaced by another one that does not dissolve porous structure and has low critical temperature [1]. Material with exchanged solvent is then put to autoclave, which allows to achieve critical temperature and pressure parameters for particular solvent. At this conditions no evaporation can appear, solvent is expelled from the material by capillary forces only, as the liquid is converted directly into permanent gas. It is crucial to exchange water to solvent having lower surface tension because at critical $T$ and $p$ water is such a powerful agent that might damage gel structure back to zol [2]. The history of organic aerogels has been started years later in the end of eighties, when Richard Pekala mixed resorcinol with formaldehyde in a proper molar ratio [3]. Aged, cross-linked gel was then treated with acetone to exchange fluid in pores. Supercritical drying in carbon dioxide atmosphere 
at critical temperature $31^{\circ} \mathrm{C}$ and critical pressure $7.4 \mathrm{MPa}$ produced monolithic resorcinol-formaldehyde aerogels [4]. Carbonization of the organic resorcinol-formaldehyde aerogels is performed to enhance their unique physical properties. Examination of carbonization temperature from $1050{ }^{\circ} \mathrm{C}$ up to $2100{ }^{\circ} \mathrm{C}$ showed that from $1800{ }^{\circ} \mathrm{C}$ partial ordering of structure can be observed with four to even ten horizontally-aligned layers [4]. This shows that temperature $1050^{\circ} \mathrm{C}$ is sufficiently high to produce amorphous nanocrystalline carbon.

The gelation process is based on polymerisation and crosslinking of monomers. Cluster formation in gelation process is strongly $\mathrm{pH}-$, temperature-, and reagents concentration- dependent. Under proper parameters the formation of $\mathrm{CH}_{2}$ bridges and $\mathrm{CH}_{2} \mathrm{OH}$ cross linking is favored [5]. In fact process is composed of addition of hydroxymethyl derivatives of resorcinol and condensation reaction to form methylene and methylene ether bridges [6].

The role of keeping appropriate initial $\mathrm{pH}$ level is attributed to the catalyst, which generally can be divided into basic and acidic [7]. The most frequently used is probably sodium carbonate, while salts and hydroxides of lithium, potassium, barium, calcium, and magnesium were also examined [8]. It was found that divalent cations accelerates faster the disappearance of formaldehyde than monovalent [9]. Additionally using larger cations the bigger clusters can be obtained which result in increased pore size characteristics [10]. Gelation using some metals may lead to coordinating bonds between metals and hydroxyl groups of the same or different aromatic rings [11]. Other metal salts were tested as well. For example refractory metal salts including chromium, molybdenum and tungsten salts. It was found that application of chromium in +6 oxidation state $\left(\left(\mathrm{NH}_{4}\right)_{2} \mathrm{CrO}_{4}\right)$ resulted in neither rigid nor even hard gel material, rather powder form was obtained. Therefore chromium nitrate with chromium at +3 state was used instead [12]. Presence of specific metal strongly influences microporosity decreasing from chromium through molybdenum to tungsten. The effect of metal catalyst in gel preparation is thought to be significant, however, it is still unclear [13]. Metals can not only tailor pore structure but increase partial graphitization of organic precursors in carbonization process as well [14]. Effect of precious metals in form of tetramineplatinum(II) chloride, palladium chloride, and silver acetate, showed possibility to produce well-developed highly porous carbon gels too [15]. It was found that platinum resulted in the biggest specific surface area close to $3000 \mathrm{~m}^{2} / \mathrm{g}$ with the greatest meso and macropore volume, while palladium and silver were microporous materials with specific surface area $1300 \mathrm{~m}^{2} / \mathrm{g}$ and $1100 \mathrm{~m}^{2} / \mathrm{g}$.

Although specific surface area is independent on the initial $\mathrm{pH}$ of precursor solution (in the range 5.5-7.5), it is strongly combined with carbonization temperature [16]. However the $\mathrm{pH}$ strongly influences the pore structure. It was found that gel prepared at neutral $\mathrm{pH}$ was composed mainly of mesopores while at $\mathrm{pH} 3$ microporous morphology was found [17]. Regarding type of catalyst used in RF polymerisation different specific surface area from tenths of $\mathrm{m}^{2} / \mathrm{g}$ to more than thousand $\mathrm{m}^{2} / \mathrm{g}$, and bulk density of material in the range $1.8-2.2 \mathrm{~g} / \mathrm{cm}^{3}$ may be obtained [18]. Effect of metal can be also found in the last step of gel preparation i.e. carbonization. As some metals like $\mathrm{Fe}^{2+}, \mathrm{Co}^{2+}, \mathrm{Ni}^{2+}$ may be responsible for partial graphitization of carbon material [19]. The general catalyst trend in carbon gels formation is to increase in average pore size and total pore volume using possibly smallest amount of catalyst i.e. high $\mathrm{R} / \mathrm{C}$ ratio [20]. At higher amount of catalyst results bigger amount of clusters are produced in addition reaction, and consequently pore size diameter is diminished.

Texture of as prepared carbon aerogels can be improved by activation either physical or chemical. The popular physical activators include steam, ammonia, carbon dioxide, while chemical is based on reagents such as potassium hydroxide, potassium carbonate or phosphoric acid [21]. Activation is able to tailor porosity, producing more microporosity, and consequently enhance the specific surface area. Proper activator may also change electrical conductivity and number of active sites as well [22].

The use of carbon gels in electrochemical applications is still limited but some examples can be found in the literature. Generally the specific capacity of carbon aerogel matrix used as electrodes in supercapacitors may vary from tens up to $240 \mathrm{~F} / \mathrm{g}$ [21]. In comparison to other type of carbons (activated carbon, graphite, graphene), carbon gels have some residual amount of heteroatoms, which are components of active sites, through which the net capacity may be increased by pseudocapacitive effects. Additionally, active sites strongly improve wettability that is important for electrolyte transport in energy storage applications. Resorcinol/formaldehyde gels impregnated by chloroplatinic acid were tested in fuel cells electrodes [23], however it was found that impregnation of metal on a prepared gel led to its poor dispersion within carbon matrix and no significant difference in characteristics with respect to bare gel was observed. RF gels modified with deposited molybdenum were examined in electrolyser operation [24]. The catalytic activity of modified gels was analyzed adding second metal to RF gels simultaneously with sodium carbonate catalyst. In such a way a vast group of materials was examined from titanium copper, and manganese, through precious metals up to refractory metals like molybdenum and tungsten [25]. 


\section{Experimental}

\subsection{Carbon aerogels preparation}

Carbon aerogels were synthesized mixing $10.64 \mathrm{~g}$ resorcinol and $15.5 \mathrm{~mL}$ formaldehyde in the presence of proper catalyst, either sodium carbonate (RF) or lithium perrhenate (RF LiRe). After 3 days mixing, the polymerized structure was aged for 7 days at $80-85^{\circ} \mathrm{C}$, and then the solvent was exchange into acetone (immersing gel into a beaker with acetone). Wet gels were supercritically dried in autoclave in supercritical acetone at $250^{\circ} \mathrm{C}$ and $6 \mathrm{MPa}$. Finally, the dried organic gels were carbonized in a Jenker's tube at $900^{\circ} \mathrm{C}$ without air supply.

\subsection{Material characterization}

The morphology was examined using high resolution scanning electron microscope Zeiss Leo Gemini 1525 , equipped with secondary electrons and backscattered electrons detectors. Nitrogen adsorption isotherms at $-196{ }^{\circ} \mathrm{C}$ were evaluated using 3Flex from Micromeritics in the relative pressure range $0.01-0.99$, using nitrogen of purity $99.998 \%$. The specific Surface area was calculated using Brunauer-Emmett-Teller (BET) method from adsorption data of a range $0.05-0.3$. Pore size and pore volume distribution were calculated with Barrett-Joyner-Halenda (BJH) method. Prior to analysis materials were dried at $110^{\circ} \mathrm{C}$ for $31 \mathrm{~h}$ and $1 \mathrm{~h}$ in vacuum. $\mathrm{X}$-ray powder diffraction was performed using Rigaku MiniFlex 600 with $\mathrm{Cu} \mathrm{K}_{\alpha}$ radiation, equipped with silicon strip detector D/teX, and Soller slits 2.5". Electrochemical analysis was performed using two electrode configuration and Auto-lab PGSTAT 302/N workstation. Electrode materials were mixed with poly(tetrafluoroethylene) and pasted on electrochemical nickel current collectors. Bothe electrodes were separated with a membranę soaked with $6 \mathrm{M} \mathrm{KOH}$. The assembly was pressed by screws in a poly(methyl methacrylate) casing. The specific capacity was calculated from galvanostatic chargé/discharge curve, capacity loss from cyclic voltammetry (CV) curves in the range $0-1 \mathrm{~V}$ with scan rate $0.5 \mathrm{~V} / \mathrm{s}$, while the resistance of the electrode processes was determined by electrochemical impedance spectroscopy (EIS), in the frequency range $100 \mathrm{kHz}-100 \mathrm{mHz}$ with the amplitude of sinusoidal voltage signal equal $10 \mathrm{mV}$.

\section{Results}

Process of carbon gels preparation was schematically presented in a Fig. 1. It is composed of several subsequent stages with supercritical drying being the most troublesome.

A newly prepared gel was thoroughly examined with respect to structural and electrochemical properties. At the beginning the morphology was analyzed to show any significant differences in materials structure using sodium carbonate or lithium perrhenate catalyst.

The structural differences of both produced gels can be found already at magnification $\times 5000$. The gel prepared with typical sodium carbonate catalyst is more dense and the main material is covered by debris of significantly smaller particles (Fig. 2a), while RF LiRe is composed of more regular particles. It can be also noticed that the surface of lithium perrhenate-catalyzed material is more exfoliated (Fig. 2b).

Bigger magnification $(\times 30,000)$ revealed corrugated morphology of RF material and more spongy-like structure of RF LiRe, in a Fig. 2c, d, respectively. This showed that lithium perrhenate catalyst produced porous material with well-developed pore structure. It was also found that RF LiRe was less fragmented after carbonization i.e. less fragile than traditional RF carbon gel.

One of the key parameter of electrode material selection is appropriately high surface area with pore size adequate for electrolyte diffusion. Application of lithium perrhenate as polymerization and cross-linking catalyst enhanced significantly the specific surface area (Table 1). This effect can be ascribed to both rhenium and lithium. From one side rhenium has a strong catalytic activity and is able to chelate organic molecules to arrange them spatially in an appropriate way. Authors have performed tests with ammonium perrhenate and perrhenic acid catalysts as well, however, in those examples the red-brown solid powder materials were precipitated during polymerisation and aging stages. The catalyst activity was very high even at big $\mathrm{R} / \mathrm{C}$ ratio. This showed that some perrhenates are more privileged than others. For example any of such problems were not observed in case of lithium perrhenate. Probably because lithium atom behaves more like divalent in gelation process (which was discussed in an introduction part). Consequently, the combination of lithium and perrhenate ions 


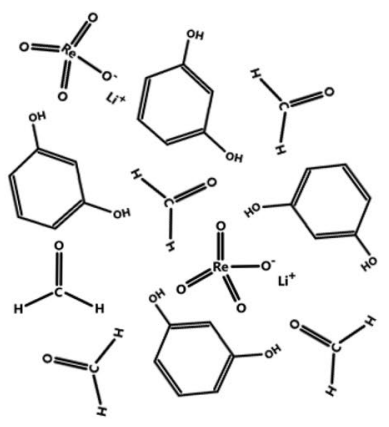

Monomers + catalyst

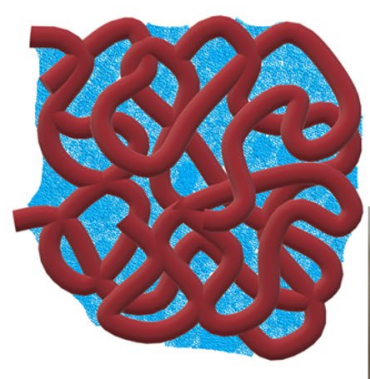

Organic wet gel

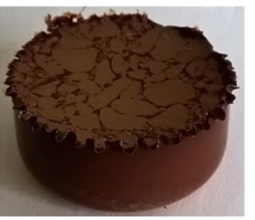

supercritical drying in acetone $250^{\circ} \mathrm{C}, 6 \mathrm{MPa}$
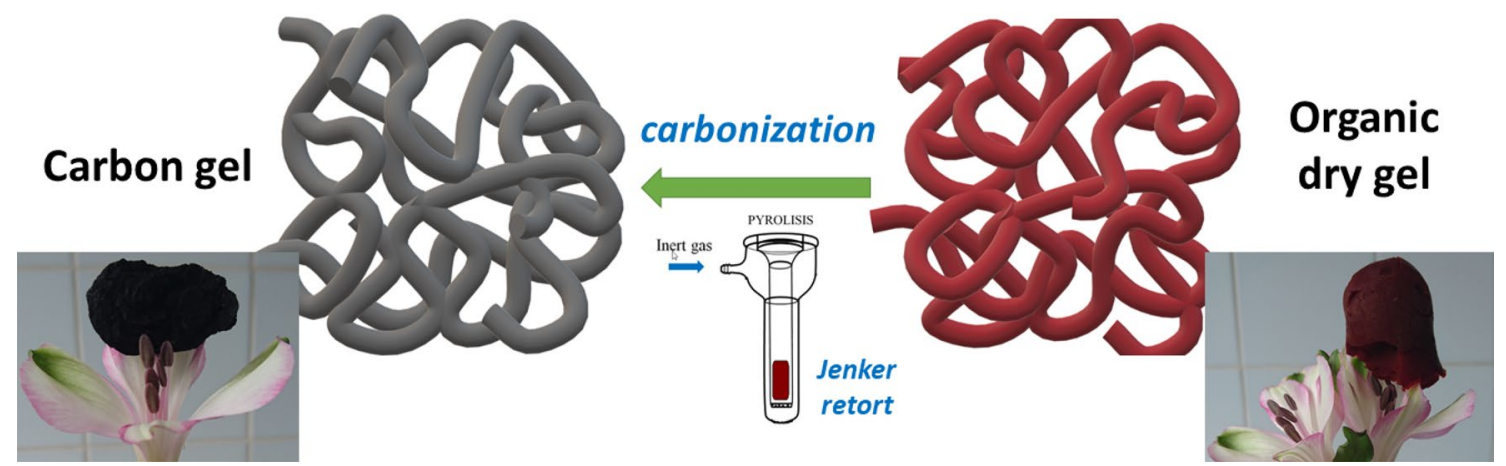

Fig. 1 Schematic presentation of carbon gel production
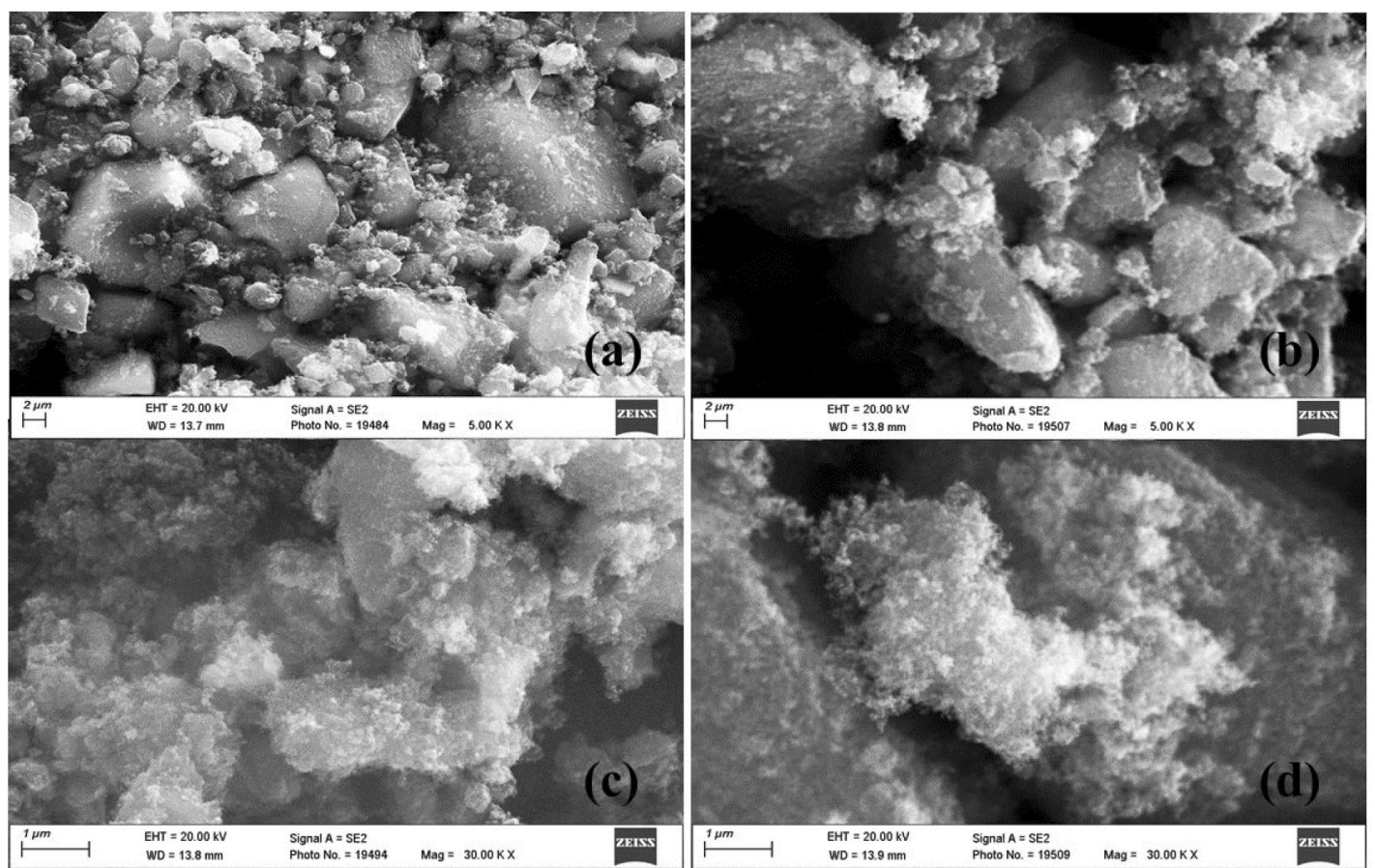

Fig. 2 SEM images for gels prepared with sodium carbonate (RF) and lithium perrhenate (RF LiRe) catalysts 
Table 1 Specific surface area and pore area calculated for carbon aerogels

\begin{tabular}{llll}
\hline Sample & $\begin{array}{l}\text { Specific surface } \\
\text { area } \\
\text { BET } / \mathrm{m}^{2} / \mathrm{g}\end{array}$ & $\begin{array}{l}\text { Pore area } \\
\text { BJH adsorption/ } \\
\mathrm{m}^{2} / \mathrm{g}\end{array}$ & $\begin{array}{l}\text { PJH desorption/ } \\
\mathrm{m}^{2} / \mathrm{g}\end{array}$ \\
\hline $\mathrm{RF}$ & $614.20 \pm 0.90$ & 521.88 & 554.76 \\
$\mathrm{RF}$ LiRe & $696.62 \pm 1.47$ & 628.66 & 552.40 \\
\hline
\end{tabular}

Table 2 Pore volume and pore size calculated for carbon aerogels

\begin{tabular}{lllll}
\hline Sample & $\begin{array}{l}\text { Pore volume } \\
\text { BJH (adsorp- } \\
\text { tion) } \mathrm{cm}^{3} / \mathrm{g}\end{array}$ & $\begin{array}{l}\text { Pore volume } \\
\text { BJH (desorp- } \\
\text { tion) } \mathrm{cm}^{3} / \mathrm{g}\end{array}$ & $\begin{array}{l}\text { Pore size } \\
\text { BJH (adsorp- } \\
\text { tion) } \mathrm{nm}\end{array}$ & $\begin{array}{l}\text { Pore size } \\
\text { BJH (des- } \\
\text { orption) } \\
\mathrm{nm}\end{array}$ \\
\hline $\mathrm{RF}$ & 1.24 & 1.87 & 9.53 & 13.49 \\
$\mathrm{RF}$ LiRe & 3.71 & 3.71 & 23.61 & 26.86 \\
\hline
\end{tabular}

was used. Divalent-like lithium boosted formaldehyde consumption while perrhenate ion coordinated resorcinol molecules. Both of them allowed to keep solution homogenous up to drying procedure.

Usually, faster polymerisation generates bigger microporosity, however, for lithium perrhenate catalyst the opposite was observed. Probably, spatial ordering of resorcinol molecules in solution slightly counteract quick consumption of formaldehyde. This produced material of reasonably big pore size. As compared to sodium carbonate-catalyzed gel the pore volume and pore size were doubled for lithium perrhenate catalyst. This is advantageous as the bigger size of pores improves penetration of pore channels by electrolyte ions in hydrated form (Table 2).

The obtained isotherms (Fig. 3) are convex with respect to pressure axis and their shape presents "the cooperative adsorption" i.e. previously adsorbed particles pursue to increase the overall adsorption. Consequently, the interaction of adsorbing particles is stronger than one between particles and adsorber. This type of isotherms are mostly assigned to microporous materials. The shape of hysteresis revealed spherical pores with numerous narrowings.

The X-ray diffraction pattern showed amorphous structure of both materials (Fig. 4). Although both were

Isotherm

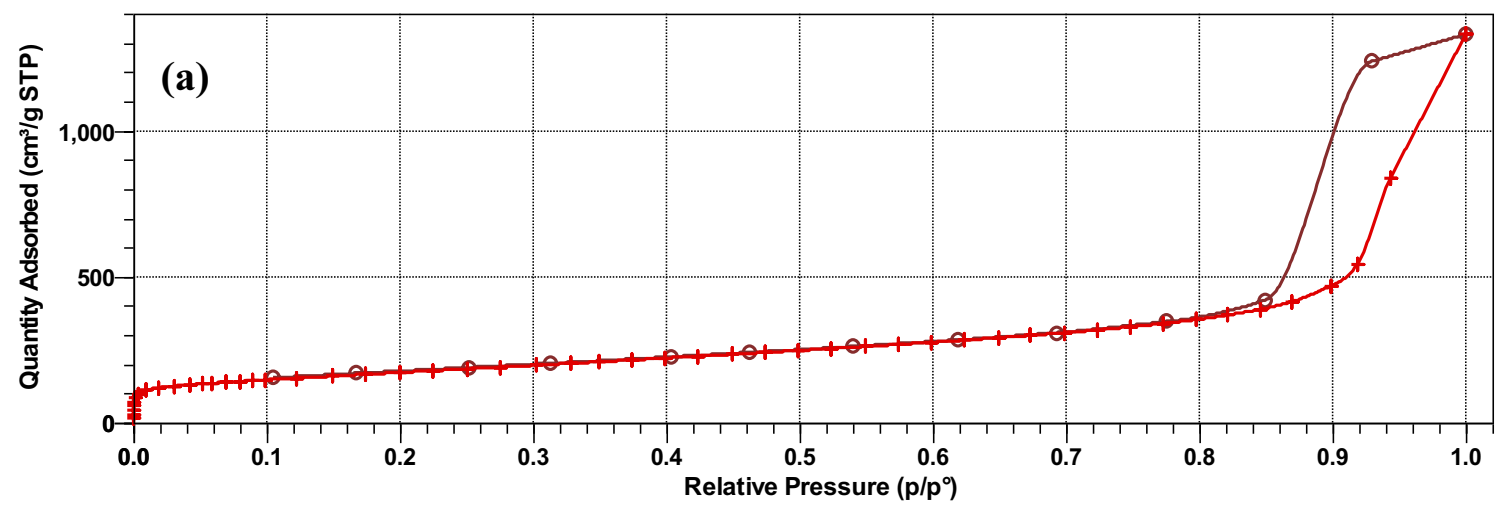

Isotherm

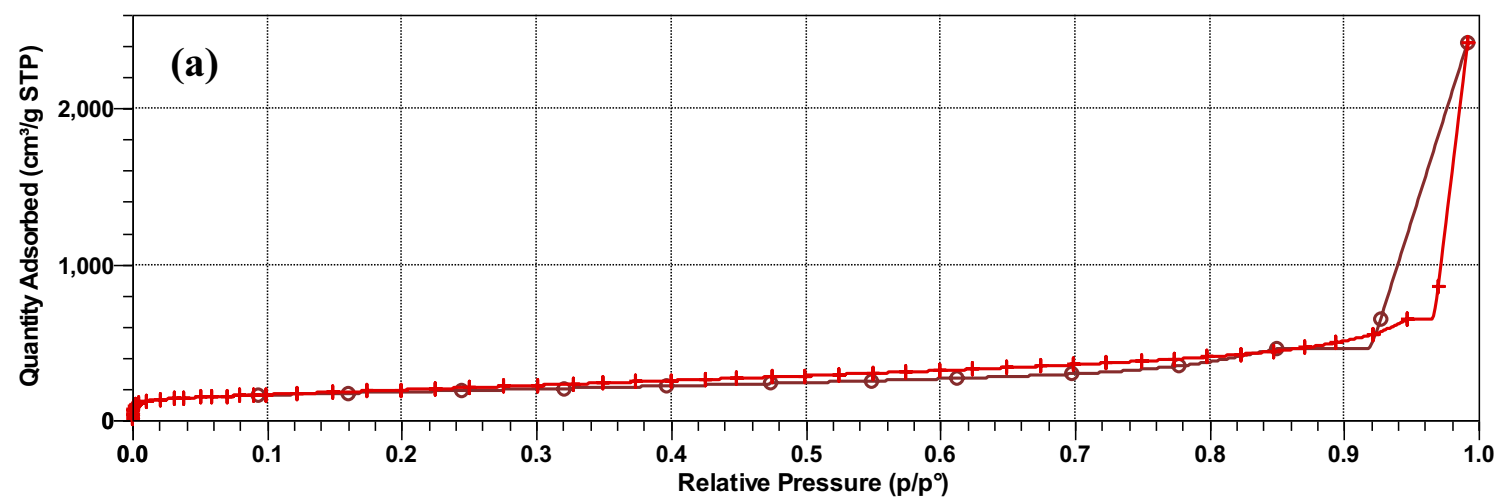

Fig. 3 Isotherms obtained for carbon aerogels prepared using sodium carbonate catalyst (a) and lithium perrhenate catalyst (b) 
Fig. 4 The X-ray powder diffraction patterns for gels prepared with sodium carbonate (RF) and lithium perrhenate (RF LiRe) catalysts

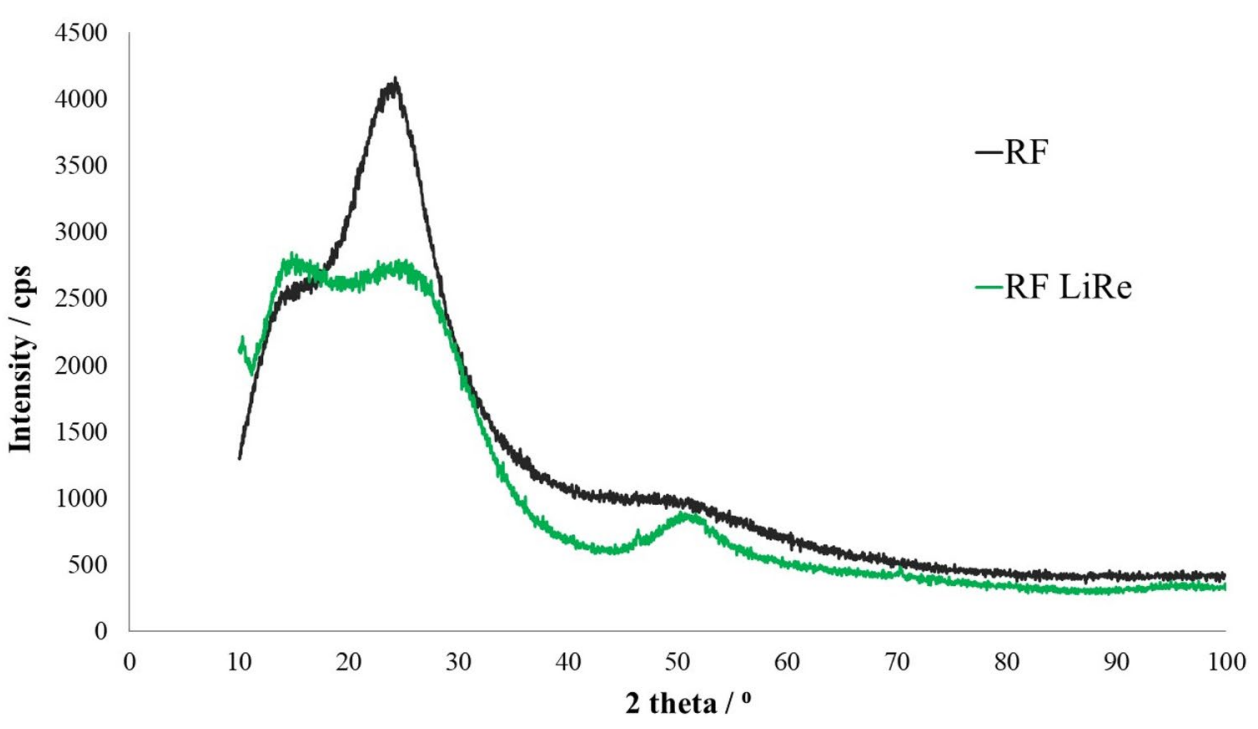

carbonized at the same temperature the intensity of RF gel graphite-like signal around $26^{\circ}$ was markedly bigger. This may indicate hindered ordering of carbon structure when using lithium perrhenate catalyst. This can be also observed by dual nature of this signal in RF LiRe, which is partially assigned to non-ordered carbon structure around $15^{\circ}$ and partially stacked around $26^{\circ}$. There were not found any signals attributed to metal catalyst, however, some low-intensity peaks (hidden in background) were observed around $45^{\circ}$ and $70^{\circ}$.

CV tests were performed to show the ability of material to withstand multiple charge discharge cycles. Electrodes were scanned with a rate $0.5 \mathrm{~V} / \mathrm{s}$ in the potential range $0-1 \mathrm{~V}$. The difference in the capacity of the first and thousandth cycle revealed the stability of electrode towards capacity loss. Actually, in both cases (RF and
RF LiRe) a slight increase in the capacity was observed by 0.7 and $2.9 \%$, for RF and RF LiRe, respectively. This is attributed to presence of functionalities within the structure, which introduced pseudocapacitance. It can be observed that the shape of RF LiRe is more rectangular (left and right hand side of plot in a Fig. 5 is on the outer part vs RF). It means that material is working more uniformly. However, both electrodes showed slight delay in charging just above $0 \mathrm{~V}$ and discharging in range 0.95-1 V, which is combined with electrolyte diffusion effectiveness.

Specific capacity was obtained from the galvanostatic charge/discharge curves, which were presented separately for two materials in a Fig. 6. Curves for RF were registered at significantly higher current density. Nevertheless how long the charging time was, at lower current
Fig. 5 CV curves for gels prepared with sodium carbonate (RF) and lithium perrhenate (RF LiRe) catalysts, registered in 1000 charge/discharge cycles

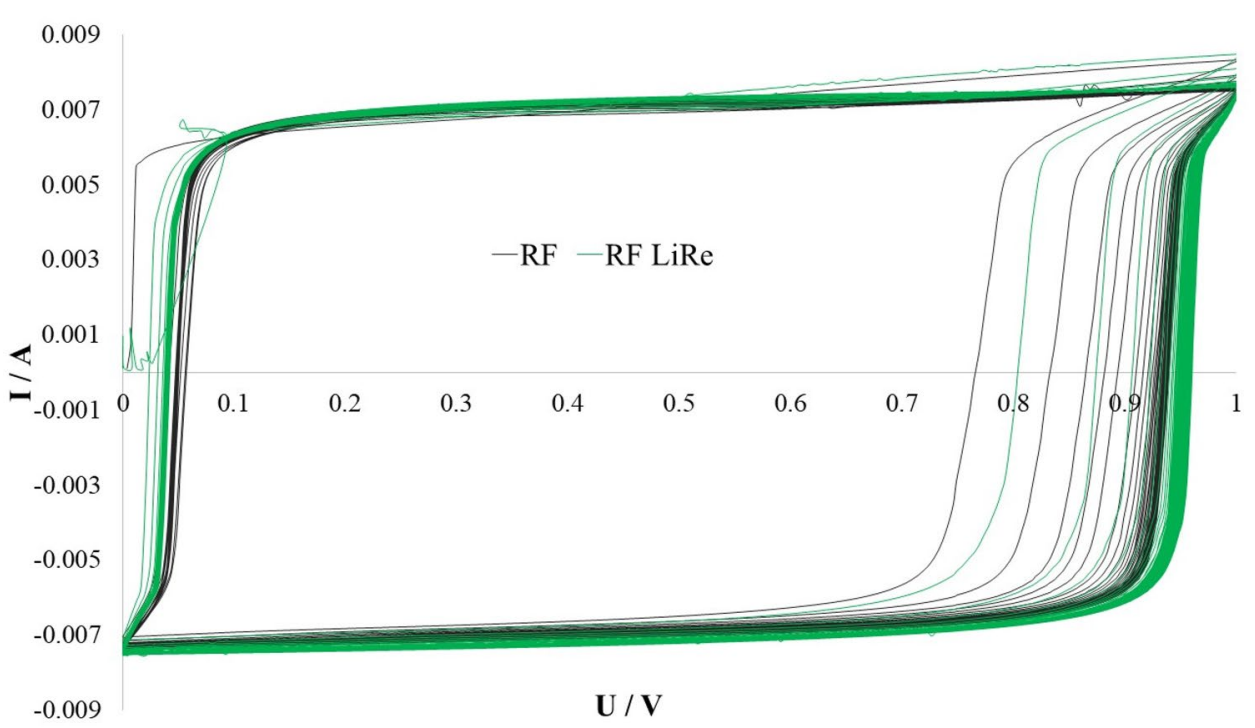

SN Applied Sciences A SPRINGER NATURE journa 

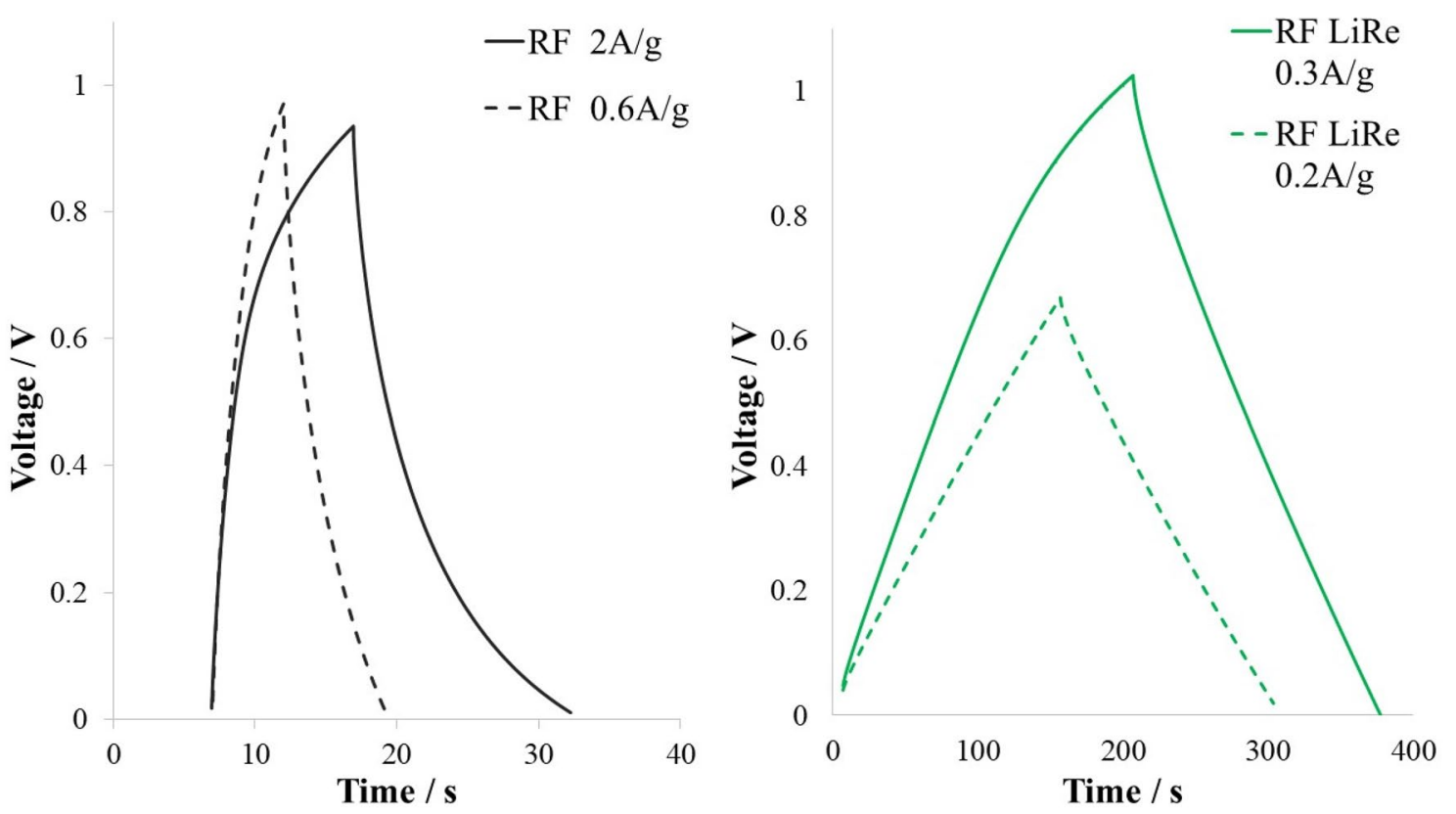

Fig. 6 Galvanostatic chargé/discharge curves obtained for gels prepared with sodium carbonate (RF) and lithium perrhenate (RF LiRe) catalysts

density (about $0.3 \mathrm{~A} / \mathrm{g}$ ) it was impossible to chargé RF above $0.5 \mathrm{~V}$. The RF curve is noticeably bent in the upper region of charge and lower region of discharge, which shows non-ideal character of the electrode processes. This effect was strongly inhibited using lithium perrhenate catalyst. The bigger pore size enabled easier transport of electrolyte and made chargé/discharge process more reversible - this can be observed at $0.2 \mathrm{~A} / \mathrm{g}$, when the ideal triangular and very symmetric curve was recorded.

The electrochemical Impedance spectroscopy measures the impedance of cell as function of frequency. Obtained data can be demonstrated graphically either as Nyquist (imaginary vs real impedance component) or Bode (phase angle vs frequency) plot. EIS is a powerful tool which allows to determine electrolyte resistance $\left(R_{S}\right)$, charge transfer resistance $\left(R_{C T}\right)$ evaluate mass transport, and energy/power properties of the analyzed material. Nyquist plots for RF and RF LiRe, presented in a Fig. 7 (full plot and high frequency region), showed quite different characteristics. The semi-circle corresponding to the Faradaic charge-transfer resistance was much bigger in case of RF. This is attributed to more developed functionalities. This heteroatoms active sites increase the net resistance of the electrode and interact with the electrolyte producing irreversible reactions. The loop is much smaller in RF LiRe satisfying improved penetration of electrode by electrolyte. Similarly a straight line in the low-frequency region, representing the ion diffusion in the electrode structure, is more steep for RF LiRe confirming better capacitive behaviour.

Data calculated from CV curves (capacity change from the 1st to 1000th cycle), galvanostatic chargé/discharge (specific capacity), and Nyquist plots (resistance) were presented in Table 3.

\section{Conclusions}

It was found that lithium perrhenate was able to effectively catalyze gelation of resorcinol-formaldehyde mixture. The produced carbon aerogel had significantly enhanced specific surface area, and better developed pore structure. Morphological analysis revealed completely changed pore size that was attributed to both lithium and rhenium interaction with monomers. Structure was more corrugated and exfoliated satisfying increased specific surface area and consequently bigger electrochemical double layer formation. Electrochemical characterization was performed in a symmetric supercapacitors assembly with an aqueous electrolyte. The multifold increase in the specific capacity of as-prepared supercapacitor was observed, however, slight increase in capacity loss after 1000 cycles was found as well. 

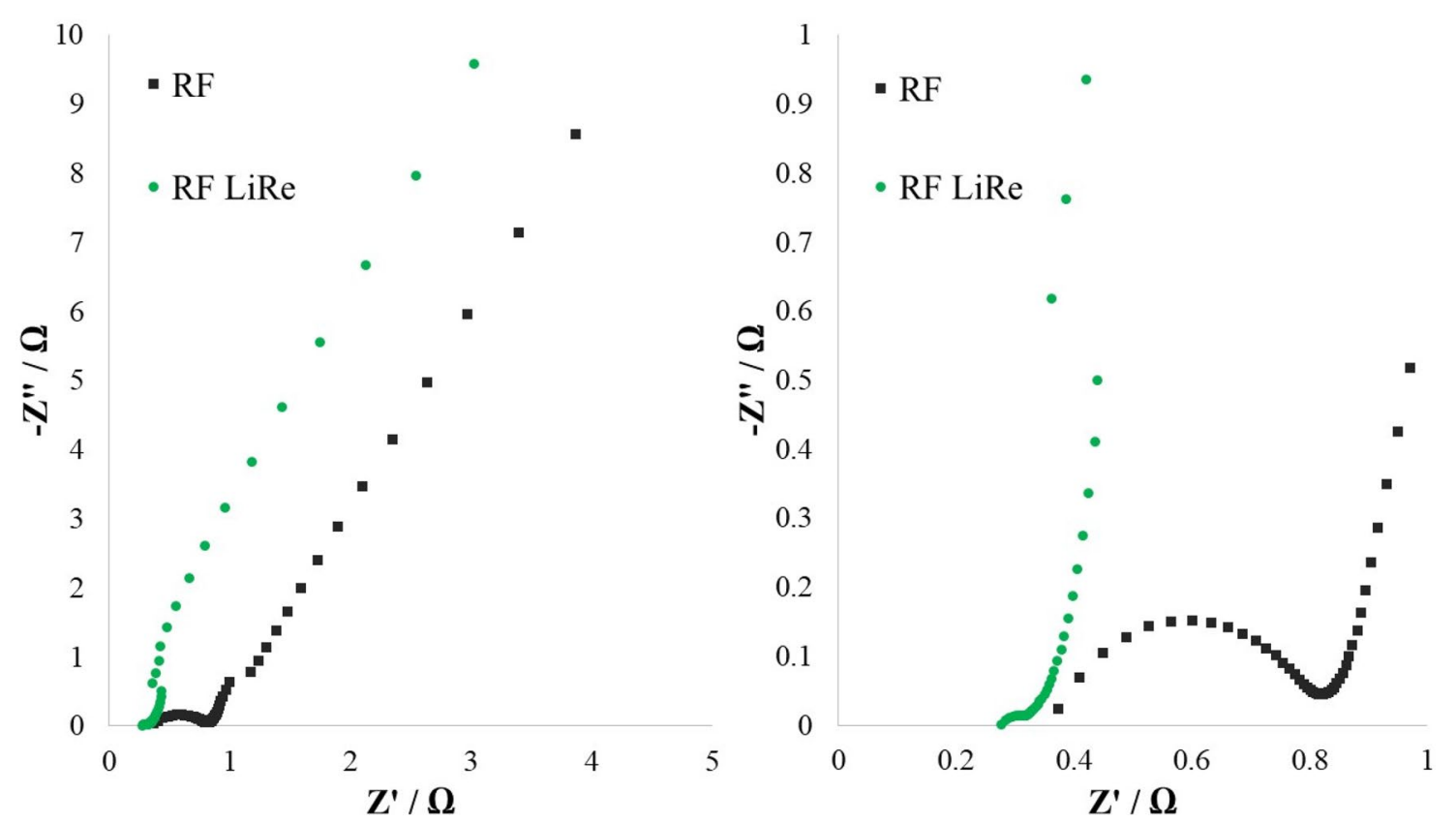

Fig. 7 Electrochemical impedance spectroscopy curves obtained for gels prepared with sodium carbonate (RF) and lithium perrhenate (RF LiRe) catalysts

Table 3 Results of the electrochemical tests of carbon aerogels prepared using different catalysts

\begin{tabular}{llllll}
\hline & $\mathrm{R}_{\mathrm{S}} / \Omega$ & $\mathrm{R}_{\mathrm{CT}} / \Omega$ & $\mathrm{Z}^{\prime} / \Omega$ & $\mathrm{C}_{\mathrm{SP}} / \mathrm{F} / \mathrm{g}$ & $\Delta \mathrm{C} / \%$ \\
\hline RF & 0.37 & 0.45 & 3.87 & 11.4 & -0.72 \\
RF LiRe & 0.27 & 0.05 & 3.03 & 74 & -2.88 \\
\hline
\end{tabular}

Acknowledgements Authors deeply appreciate contribution of Grzegorz Muzia for his scanning electron microscope analysis and also would like to thank to Łukasz Hawełek for x-ray powder diffraction examinations.

Funding This work was funded by statutory grant from the Łukasiewicz Research Network-Institute of Non-Ferrous Metals in Gliwice, Poland, entitled "Modyfikacja cząstkami renu wyselekcjonowanych materiałów węglowych" [Selected carbon materials modified by rhenium compounds], No. 4/G/S/2018.

\section{Compliance with ethical standards}

Conflict of interest The authors declare that they have no conflict of interest.

Open Access This article is licensed under a Creative Commons Attribution 4.0 International License, which permits use, sharing, adaptation, distribution and reproduction in any medium or format, as long as you give appropriate credit to the original author(s) and the source, provide a link to the Creative Commons licence, and indicate if changes were made. The images or other third party material in this article are included in the article's Creative Commons licence, unless indicated otherwise in a credit line to the material. If material is not included in the article's Creative Commons licence and your intended use is not permitted by statutory regulation or exceeds the permitted use, you will need to obtain permission directly from the copyright holder. To view a copy of this licence, visit http://creativecommons .org/licenses/by/4.0/.

\section{References}

1. Kistler SS (1931) Coherent expanded aerogels and jellies. Nature 127:741

2. Kistler SS (1932) Coherent expanded aerogels. J Phys Chem 36:52-64

3. Pekala RW (1989) Organic aerogels from the polycondensation of resorcinol with formaldehyde. J Mater Sci 24(9):3221-3227

4. Pekala RW, Mayer ST, Kaschmitter JL, Kong FM (1994) Carbon aerogels: an update on structure, properties, and applications. In: Attia YA (ed) Sol-gel processing and applications. Plenum Press, New York, pp 369-377

5. Aegerter MA, Leventis N, Koebel MM (2011) Advances in solgel derived materials and technologies, aerogels handbook. Springer, New York

6. Lin C, Ritter JA (1997) Effect of synthesis $\mathrm{pH}$ on the structure of carbon xerogel. Carbon 35(9):1271

7. Job N, Théry A, Pirard R, Marien J, Kocon L, Rouzaud J-N, Béguin F, Pirard J-P (2005) Carbon aerogels, cryogels and xerogels: influence of the drying method on the textural properties of porous carbon materials. Carbon 43(12):2481-2494

8. Zhang W, Huang ZH, Zhou C, Cao G, Kang F, Yang Y (2012) Porous carbon for electrochemical capacitors prepared from a resorcinol/formaldehyde-based organic aquagel with nano-sized particles. J Mater Chem 22:7158-7163 
9. Grenier-Loustalot M-F, Larroque S, Grande D, Grenier P, Bedel D (1996) Phenolic resins: 2 . Influence of catalyst type on reaction mechanisms and kinetics. Polymer 37(8):1363-1369

10. Lu AH, Li W-C, Schu F (2005) Preparation of monolithic carbon aerogels and investigation of their pore interconnectivity by a nanocasting pathway. Chem Mater 17:3620-3626

11. Galaburda MV, Bogatyrov VM, Skubiszewska-Zięba J, Oranska OI, Sternik D, Gun'ko VM (2016) Synthesis and structural features of resorcinol-formaldehyde resin chars containing nickel nanoparticles. Appl Surf Sci 360:722-730

12. Moreno-Castilla C, Maldonado-Hodar FJ, Rivera-Utrilla J, Rodrıguez-Castellon E (1999) Group 6 metal oxide-carbon aerogels. Their synthesis, characterization and catalytic activity in the skeletal isomerization of 1-butene. Appl Catal A Gen 183:345-356

13. Maldonado-Hódar FJ, Pérez-Cadenas AF, Moreno-Castilla $C$ (2003) Morphology of heat-treated tungsten doped monolithic carbon aerogels. Carbon 41(6):1291-1299

14. Maldonado-Hódar FJ, Moreno-Castilla C, Rivera-Utrilla J, Hanzawa Y, Yamada Y (2000) Catalytic graphitization of carbon aerogels by transition metals. Langmuir 16(9):4367-4373

15. Maldonado-Hodar FJ, Ferro-Garcia MA, Rivera-Utrilla J, MorenoCastilla C (1999) Synthesis and textural characteristics of organic aerogels, transition-metal-containing organic aerogels and their carbonized derivatives. Carbon 37:1199-1205

16. Job N, Pirard R, Marien J, Pirard J-P (2004) Porous carbon xerogels with texture tailored by $\mathrm{pH}$ controlduring sol-gel proces. Carbon 42:619-628

17. Bekyarova E, Kaneko K (2000) Structure and physical properties of tailor-made Ce, Zr-doped carbon aerogels. Adv Mater 12:1625-1628

18. Horikawa T, Hayashi J, Muroyama K (2004) Controllability of pore characteristics of resorcinol-formaldehyde carbon aerogel. Carbon 42(8-9):1625-1633
19. Fu R, Dresselhaus MS, Dresselhaus G, Zheng B, Liu J, Satcher J Jr, Baumann TF (2003) The growth of carbon nanostructures on cobalt-doped carbon aerogels. J Non-Cryst Solids 318:223-232

20. Yang I, Kim SG, Kwon SH, Kim MS, Jung JC (2017) Relationships between pore size and charge transfer resistance of carbon aerogels for organic electric double-layer capacitor electrodes. Electrochim Acta 223:21-30

21. Li F, Xie L, Sun G, Kong Q, Su F, Cao Y, Wei J, Ahmad A, Guo X, Chen C-M (2019) Resorcinol-formaldehyde based carbon aerogel: preparation, structure and applications in energy storage devices. Microporous Mesoporous Mater 279:293-315

22. Wang $Y$, Liu H, Wang K, Song S, Tsiakaras P (2017) 3D interconnected hierarchically porous $\mathrm{N}$-doped carbon with $\mathrm{NH}_{3}$ activation for efficient oxygen reduction reaction. Appl Catal B Environ 210:57-66

23. Pajonk GM, Venkateswara Rao A, Pinto N, Ehrburger-Dolle F, Bellido Gil M (1998) Monolithic carbon aerogels for fuel cell electrodes. In: Delmon B et al (eds) Preparation of catalysts VII. Elsevier, Amsterdam, pp 167-174

24. Douglas TG, Cruden AJ, Infield D, Roy A, Hall P (2011) Investigation of molybdenum (resorcinol-formaldehyde) (Mo-RF) electrode for alkaline electrolyser operation. Int J Hydrog Energy 36:7791-7798

25. Nagy B, Ábrahám D, Dobos G, Madarász J, Onyestyák G, Sáfrán G, Geissler E, László K (2014) Molybdenum doped carbon aerogels with catalytic potential. Carbon 66:210-218

Publisher's Note Springer Nature remains neutral with regard to jurisdictional claims in published maps and institutional affiliations. 